\title{
Factors Influencing the Surgical Outcomes of Extradural Haematoma
}

\author{
Md. Abdus Salam¹, Kalim Uddin², Md. Abdullah Yusuf, Md. Mahfuzur Rahman, Amir Mohammad Khan', \\ Md. Ashraful Hoque ${ }^{6}$, Md. Rafiqul Islam7, Md. Sirajul Islam ${ }^{8}$, Sudipto Kumar Mukharjee ${ }^{9}$
}

\begin{abstract}
1Associate Professor \& Head, Department of Neurotrauma Surgery, National Institute of Neurosciences \& Hospital, Dhaka, Bangladesh; 2Assistant Professor (Neurosurgery), Department of Neurotrauma Surgery, National Institute of Neurosciences \& Hospital, Dhaka, Bangladesh; 3Associate Professor, Department of Microbiology, National Institute of Neurosciences \& Hospital, Dhaka, Bangladesh; 4Associate Professor, Department of Neurotrauma Surgery, National Institute of Neurosciences \& Hospital, Dhaka, Bangladesh; 5Associate Professor, Department of Neurosurgery, National Institute of Neurosciences \& Hospital, Dhaka, Bangladesh; 6Assistant Professor, Department of Neurosurgery, National Institute of Neurosciences \& Hospital, Dhaka, Bangladesh; 7Assistant Professor, Department of Neurosurgery, National Institute of Neurosciences \& Hospital, Dhaka, Bangladesh; 8Assistant Professor, Department of Critical Care Medicine, National Institute of Neurosciences \& Hospital, Dhaka, Bangladesh; 9Associate Professor, Department of Paediatric Neurosurgery, National Institute of Neurosciences \& Hospital, Dhaka, Bangladesh;
\end{abstract}

[Received on: 22 November 2020; Accepted on: 12 December 2020; Published: 1 January 2021]

\begin{abstract}
Background: Extradural Haematoma can occur in different reasons. Objective: The purpose of the present study was to see the factors influencing the surgical outcomes of extradural haematoma. Methodology: This cross-sectional study was conducted in the Department of Neurosurgery at Dhaka Medical College Hospital, Dhaka, Bangladesh from January 2010 to June 2011 for a period of one year and six months. All patients presented with traumatic head injury having extradural haematoma in any age with both sexes who were underwent surgical or conservative management were selected as study population. The etiologies of head injuries were recorded. Result: Eighty (80) patients of traumatic head injury within and after 24 hours of head injury were enrolled in this study. In this study road traffic accident was the most common mode of injury which was 51(63.8\%) cases followed by fall from height and assault which were 16(20.0\%) cases and 13(16.2) cases respectively. Majority patients were recovered in good condition either surgery or conservative management which was $50(62.5 \%)$ cases. However, the moderate disability was reported in $17(21.2 \%)$ cases. Severe disability was found in $8(10.0 \%)$ cases. Persistent vegetative state was found in only 2 cases in conservative treatment. Death was found in $3(3.8 \%)$ cases. Conclusion: In conclusion road traffic accident is the most common mode of injury among the study population that causes extra dura haematoma which has the role as factors that influence the outcomes of the patients. [Journal of National Institute of Neurosciences Bangladesh, January 2021;7(1): 65-68]
\end{abstract}

Keywords: : Extradural haematoma; traumatic head injury; road traffic accident; assault

Correspondence: Dr. Md. Abdus Salam, Associate Professor, Department of Neurotrauma, National Institute of Neurosciences \& Hospital, Dhaka, Bangladesh; Email: drsalamnins@gmail.com; Cell no.: +8801714073094

Conflict of interest: All authors had declared that there was financial conflict of interest of this research work.

Funding agency: Any of the author did not receive any external funding for this study.

Contribution to authors: Salam MA, Uddin K was involved in the concept, study design and data collection. Salam MA and Yusuf MA had prepared the manuscript. The rest of the authors were involved in data collection and partially writing and editing the manuscript.

How to cite this article: Salam MA, Uddin K, Yusuf MA, Rahman MM, Khan AM, Hoque MA, Islam MR, Islam MS, Mukharjee SK. Etiological Factors of Extradural Haematoma: Experience of 80 Cases in Bangladesh. J Natl Inst Neurosci Bangladesh, 2021;7(1): 65-68

Copyright: (C2021. Salam et al. Published by Journal of National Institute of Neurosciences Bangladesh. This article is published under the Creative Commons CC BY-NC License (https://creativecommons.org/licenses/by-nc/4.0/). This license permits use, distribution and reproduction in any medium, provided the original work is properly cited, and is not used for commercial purposes.

\section{Introduction}

Extradural haematoma with cerebral compression is one of the most urgent of all surgical emergencies ${ }^{1}$. Treated in time the patient can make full recovery. Failure to diagnose and delayed operation definitely lead to death. This is one of the direst of all neurosurgical 
emergencies ${ }^{2}$.

Head injury is a serious health problem in all nations and it is a significant factor for approximately half of all deaths related to trauma and the main cause of head trauma includes road traffic accident, assaults, fall from height, sports injuries and industrial accidents ${ }^{3}$. The extradural haematoma is a collection of blood between the skull and the dura mater. It is caused by a ruptured artery or vein in the epidural space as a result of a fracture of the skull at the moment of the impact in 60.0 to $90.0 \%$ of cases $^{4}$. In children fractures are less common $^{5}$. Extradural haematomas (EDH) develops in 1.0 to $3.0 \%$ of all major head injuries and are most common in the young male in the second and third decades of life $^{6}$. Extradural haematomas $(\mathrm{EDH})$ usually occurs in young adults and is rare before age 2 years or after age 60 perhaps because the dura is more adherent to the inner table in these groups ${ }^{7}$.

Extradural haematoma can result from injury to the middle meningeal artery, the middle meningeal vein, the diploic veins or the venous sinuses ${ }^{8}$. Historically bleeding from the middle meningeal artery has been considered the main source for extradural haematomas 9 . Yong $^{10}$ found extradural haematoma $(\mathrm{EDH})$, in $2.0 \%$ of all serious head injuries, uncommon in infants and associated with skull fracture in 40.0 to $85.0 \%$ cases $^{10}$. Extradural haematoma which lies in between the inner surface of skull and strips of dural membrane are nearly always caused by and located near to a skull fracture. The collection takes several forms in terms of size, location, speed development and effects they exert on patient. Extradural haematoma (EDH) usually forms within an hour from the time of injury but sometimes run a more chronic course. Extradural haematoma is more common in some areas, temporal and temporo-parietal areas are involved in $70 \%$ cases approximately ${ }^{11}$. The rest occur in the frontal, occipital and posterior fossa ${ }^{8}$. The purpose of the present study was to see the etiologies of patients presented with extra dura haematoma.

\section{Methodology}

This cross-sectional study was carried out from January 2010 to June 2011 for a period of one year and six months. This study was carried out in the Department of Neurosurgery at Dhaka Medical College Hospital, Dhaka, Bangladesh. All patients presented with traumatic head injury having extradural haematoma in any age with both sexes who were underwent surgical management were selected as study population. The etiologies of head injuries were recorded. Purposive sampling technique was done. Patients with traumatic extradural haematoma diagnosed clinically by classical presentation of EDI-I and radiologically by non-contrast CT-scan of brain all of "whom underwent surgery. In all cases traumatic extradural haematoma were supratentorial. Non-traumatic extradural haematoma, patients with bilateral extradural haematoma, posterior fossa extradural haematoma and patients on anticoagulant therapy were excluded from this study. At admission, a detailed history of the illness was taken from the patients/patient's attendants by face-to-face interview with the help of a pre-formed questionnaire. Questionnaire was prepared with key variables like age, sex and mode of injury. All the data were checked and edited after collection. Then the data were entered into computer and statistical analysis of the results was obtained by using window based computer software devised with Statistical Packages for Social Sciences (SPSS-16) (SPSS Inc, Chicago, IL, USA). Prior to the commencement of this study, the ethical committee of Dhaka Medical College, Dhaka, approved the thesis protocol. The aims and objectives of the study along with its procedure, risks and benefits of this study were explained to the respondents in easily understandable language and then written consent was taken from each. It was assured that all information and records would be kept confidential and the procedure would be helpful for the neurosurgeon and the patients in subsequent management.

\section{Results}

A total number of eighty (80) patients of traumatic head injury within and after 24 hours of head injury were enrolled in this study. $7(8.7 \%)$ patients were in the less than or equal to 10 years age group. 20(25.1\%) patients were present in age group of 11 to 20 years. $19(23.8 \%)$ patients were in age group of 21 to 30 years. 20(25.1\%) patients were present in age group of 31 to 40 years. $7(8.7 \%)$ patients were in the 41 to 50 years age group and more than 50 years in each. In this study the patient's age ranged from 3 years to 64 years (Table 1).

Table 1: Age Distribution of the Study Population $(n=80)$

\begin{tabular}{lcc}
\hline Age Group & Frequency & Percent \\
\hline Less Than or Equal to 10 years & 7 & 8.7 \\
11 to 20 years & 20 & 25.1 \\
21 to 30 years & 19 & 23.8 \\
31 to 40 years & 20 & 25.0 \\
41 to 50 years & 7 & 8.7 \\
More than 50 years & 7 & 8.7 \\
Total & $\mathbf{8 0}$ & $\mathbf{1 0 0 . 0}$ \\
\hline
\end{tabular}


In this study male was predominant than female which was $60(75.0 \%)$ cases and $20(25.0 \%)$ cases respectively. The ratio of male and female was 3:1 (Table 2).

Table 2: Gender Distribution of Study population $(\mathrm{n}=80)$

\begin{tabular}{lcc}
\hline Gender & Frequency & Percent \\
\hline Male & 60 & 75.0 \\
Female & 20 & 25.0 \\
Total & $\mathbf{8 0}$ & $\mathbf{1 0 0 . 0}$ \\
\hline
\end{tabular}

The mode of injury of the patients were recorded. In this study road traffic accident was the most common mode of injury which was 51(63.8\%) cases. However a large number of patients were given the history of fall from height which was $16(20.0 \%)$ cases. Furthermore assault was reported in 13(16.2) cases (Table 3).

Table 3: Distribution of the Study Population by Mode of Injury $(n=80)$

\begin{tabular}{lcc}
\hline Mode of Injury & Frequency & Percent \\
\hline RTA & 51 & 63.8 \\
Fall from height & 16 & 20.0 \\
Assault & 13 & 16.2 \\
Total & $\mathbf{8 0}$ & $\mathbf{1 0 0 . 0}$ \\
\hline
\end{tabular}

Majority patients were recovered in good condition either surgery or conservative management which was $50(62.5 \%)$ cases. However, the moderate disability was reported in $17(21.2 \%)$ cases. Severe disability was found in $8(10.0 \%)$ cases. Persistent vegetative state was found in only 2 cases in conservative treatment. Death was found in $3(3.8 \%)$ cases (Table 4$)$.

Table 4: Distribution of Glasgow Outcome Scale during Discharge

\begin{tabular}{lcc}
\hline Glasgow Outcome Scale & Frequency & Percent \\
\hline 5-(Good recovery) & 50 & 62.5 \\
4-(Moderate disability) & 17 & 21.2 \\
3-(Severe disability) & 8 & 10.0 \\
2-(Persistent vegetative state) & 2 & 2.5 \\
1-(Death) & 3 & 3.8 \\
Total & $\mathbf{8 0}$ & $\mathbf{1 0 0 . 0}$ \\
\hline
\end{tabular}

\section{Discussion}

Extradural haematoma (EDH) is considered among the most rewardingly responsive traumatic lesions treated by neurosurgeons. The prognosis is nevertheless influenced by: age, degree of coma, pupillary reaction to light, size and site of haematoma and the mechanism of injury ${ }^{12}$. Delayed operative treatment of EDH is recognized as a poor prognostic factor. With the availability of the CT scan, early diagnosis of EDH is easier ${ }^{10}$.

In Bangladesh, excellent outcome in extradural haematoma at international level is difficult to achieve because health infrastructure is not at its best ${ }^{6}$. Neurosurgical services are not available in all district hospitals even not in all medical college hospitals. Modern diagnostic tools like CT and MRI are not available at periphery. Neurosurgeons are not in enough numbers. Therefore the diagnosis becomes late. Usually patients from interior area of the country first touches the Upazilla health complex then is referred to district hospitals or to regional medical college hospitals then neurosurgical centre. By this time patients level of consciousness gradually deteriorates with the development of secondary brain damage. Patient with EDH reaches the neurosurgical centre when they are already in coma causing poor outcome although surgically managed ${ }^{13}$. The aim of head injury management is twofold: to prevent mortality and to preserve the functioning of the neural tissue as far as possible. The management during the first hour following trauma is considered as golden hour, which will largely determine the degree of morbidity and the ultimate result ${ }^{14}$.

A total number of eighty (80) patients of traumatic head injury within and after 24 hours of head injury were enrolled in this study. $7(8.7 \%)$ patients were in the less than or equal to 10 years age group. 20(25.1\%) patients were present in age group of 11 to 20 years. $19(23.8 \%)$ patients were in age group of 21 to 30 years. $20(25.1 \%)$ patients were present in age group of 31 to 40 years. $7(8.7 \%)$ patients were in the 41 to 50 years age group and more than 50 years in each. In this study the patient's age ranged from 3 years to 64 years. In study the patient's age ranged from 3 years to 64 years irrespective to sex. In Khaled et $\mathrm{a}^{15}$ series patients' age ranged from 2.5 years to 83 years. Highest numbers of patients were in the third decade $(29 \%)$ followed by second decade $(27.55 \%)$. Only $4.92 \%$ were above the age of 50 years. Kalyanaraman et all6 found the maximum incidence was usually between the ages of 11-60 years.

In this study male was predominant than female which was $60(75.0 \%)$ cases and $20(25.0 \%)$ cases respectively. The ratio of male and female was $3: 1$. In Khaled et al ${ }^{15}$ series male and female ratio was 6.27:1. Ayub et all found male to female ratio of 5:1. Male dominant is a reflection of the social culture and most of them are exposed to external works.

The mode of injury of the patients were recorded. In 
this study road traffic accident was the most common mode of injury which was 51(63.8\%) cases. However a large number of patients were given the history of fall from height which was $16(20.0 \%)$ cases. Furthermore assault was reported in 13(16.2) cases. In Ramzan et al ${ }^{17}$ series the commonest mode of injury was RTA $(50.0 \%)$ followed by fall from height $(50.0 \%)$. Kelly and Becker $^{18}$ found $50.0 \%$ were victims of motor vehicle accidents followed by falls, which account for $30.0 \%$ and the remainder was accounted for by acts of violence and sports-related injury $0.0 \%$. By preventing delay in admission, investigation and necessary treatment the mortality of EDH could be reduced to $5 \%$ only 9 . It has been pointed out that associated brain injury, volume and density of the clot, degree of brain shift and obliteration of the basal cisterns are significantly correlated with functional outcome of EDH treated surgically ${ }^{13}$. The most significant factors associated with unfavorable outcome were higher age, lower GCS, delayed operation and higher extradural hematoma volume.

\section{Conclusion}

In conclusion male is more predominant than female. Young adult are the most common age group. In this study road traffic accident is the most common mode of injury. However a large number of patients have given the history of fall from height. Majority patients were recovered in good condition either surgery or conservative management. However, the moderate disability is also reported in cases. Severe disability is found. Further large scale study should be conducted to see the real scenario of this country.

\section{References}

1. Ayub S, Ali M, Ilyas M. Acute extra dural haematoma: factors affecting the outcome. Journal of Postgraduate Medical Institute 2005;19(2):208-11

2. Ramamurthy B, Tandon PN. Extradural Haematomas: Textbook of Neurosurgery. 1995, 2ed, New Delhi: Churchill Livingstone. 3. Hyder AA, Wunderlich CA, Puvanachandra P, Gururaj G, Kobusingye OC. The impact of traumatic brain injuries: a global perspective. Neuro Rehabilitation. 2007;22(5):341-53

4. Gean AD, Fischbein NJ, Purcell DD, Aiken AH, Manley GT, Stiver SI. Benign anterior temporal epidural hematoma: indolent lesion with a characteristic CT imaging appearance after blunt head trauma. Radiology. 2010 Oct;257(1):212-8

5. Helmy A, Vizcaychipi M, Gupta AK. Traumatic brain injury: intensive care management. British journal of anaesthesia. 2007 Jun 6;99(1):32-42

6. Tsang KK, Whitfield PC. Traumatic brain injury: review of current management strategies. British Journal of Oral and Maxillofacial Surgery. 2012 Jun 1;50(4):298-308

7. Hossain SS. Extradural haematoma in children: surgical experiences and prospective analysis of 170 cases. Turkish neurosurgery. 2012;22(1):39-43

8. Greenberg MS. Epidural Haematoma. In: Handbook of Neurosurgery, 6th ed, New York: Thieme, 2010

9. Babu ML, Bhasin SK, Kumar A. Extradural hematoma-an experience of 300 cases. JK Science. 2005;7(4):205-7

10. Young HH. Epidural Haematoma. Chorus 2004;26:1-4

11. Bullock MR, Chesnut R, Ghajar J, Gordon D, Hartl R, Newell DW, Servadei F, Walters BC, Wilberger JE; Surgical Management of Traumatic Brain Injury Author Group. Surgical management of acute epidural hematomas. Neurosurgery. 2006;58(3 Suppl):S7-15 12. Barnett, T.,C. \& Meirowsky, A.,M. 1955. Intra cranial haematomas associated with penetrating Wounds ofthe brain. J Neurosurgery, 12, 34-38

13. Jamous MA, Aziz HA, Al Kaisy F, Eloqayli H, Azab M, Al-Jarrah M. Conservative management of acute epidural hematoma in a pediatric age group. Pediatric neurosurgery. 2009;45(3):181-4.

14. Helmy A, Vizcaychipi M, Gupta AK. Traumatic brain injury: intensive care management. British journal of anaesthesia. 2007 Jun 6;99(1):32-42

15. Khaled CN, Raihan MZ, Chowdhury FH, Ashadullah AT, Sarkar MH, Hossain SS. Surgical management of traumatic extradural haematoma: Experiences with 610 patients and prospective analysis. The Indian Journal of Neurotrauma. 2008;5(2):75-9

16. Kalyanaraman S, Ramamoorthy K, Ramamurthi B. An analysis of two thousand cases of head injury. 2001;18 (Suppl):3

17. Ramzan A, Wani A, Malik AH, Kirmani A, Wani M. Acute bilateral extradural hematomas. Neurology India. 2002;50(2):217 18. Kelly DF, Becker DP. Advances in management of neurosurgical trauma: USA and Canada. World journal of surgery. 2001;25(9):1179 